International Journal of Engineering \& Technology, 9(2)(2020) 359-366
International Journal of Engineering \& Technology
SPC
Website: www.sciencepubco.com/index.php/IJET
Research paper

\title{
Analytical model for prediction of temperature distribution in early age mass concrete
}

\author{
Ugwuanyi Donald Chidiebere $^{1 *}$, Okafor Fidelis Onyebuchi ${ }^{1}$ \\ ${ }^{1}$ Department of Civil Engineering, University of Nigeria, Nsukka. Nigeria. \\ *Corresponding author E-mail: chididonald1981@gmail.com
}

\begin{abstract}
Thermally induced cracks have far-reaching implications on the durability of concrete structures. When cement mixes with water, the reaction is exothermic implying the release of heat. In the case of mass concrete structures, quite a substantial increase in internal temperature may be experienced depending on the ambient temperature and cement content in the mix. The objective of the paper is to develop a mathematical model to predict the time dependent temperature profile in early age mass concrete. Mass concrete block was used to verify the model. Type-K thermocouples placed at various positions and digital thermometer was used to monitor the temperature distribution within the mass concrete block at intervals. The highest temperature values occurred within the core of the mass concrete after one day of concrete placement. Analytical model was developed by applying method of separation of variables and orthogonality relation to two dimensional unsteady state heat conduction equations. The model equation was evaluated and using MATLAB based computer programe. The model successfully predicted the temperature variation within the mass concrete with time. It is therefore suitable for use in the assessment of thermal cracks potential in mass concrete structures.
\end{abstract}

Keywords: Analytical Model; Thermal Cracks; Mass Concrete; Orthogonality Relations; Separation of Variables

\section{Introduction}

The heat generated as a result of hydration of cement paste in mass concretes can easily dissipate at the surface, but may be trapped in the interior resulting in thermal or temperature gradient. Consequently, internal restraint arises and the thermal expansion which is as a result of temperature increase is unequal in various parts of the concrete mass. This will induce stresses, compressive in one part and tensile in the other part of the concrete mass. If the tensile stress at the surface, a consequence to the expansion that takes place at the interior of the mass concrete, exceeds the tensile strength of the concrete, surface cracks will develop. The essence of monitoring temperature in mass concrete is to control thermal cracks and issues related to durability.

Cracks may lead to rust in the concrete structure due to the possibility of chloride ions from highly saline waters penetrating to the reinforcement steel through the cracks [1]. It is quite a challenging task to model early age hardening concrete owing to its complex composite nature which undergoes changes as hydration of cement paste progresses [2]. [3] utilized heat and moisture transport model in early age hardening concrete to predict heat generated during the hydration of cement paste. [4] studied the suitability of cement based materials namely fly ash, slags and silica fumes in partially replacing cement in production of mass concrete. They inferred that blended cements have potentials to serve as a reliable substitute to low heat Portland cement in massive concrete structures. [5] studied the temperature rise properties of blast furnace slag cement concrete under adiabatic conditions. They recorded significant reduction in peak temperatures and the rate of increase in temperature with over 50\% replacement. [6] on the prospects of controlling thermal cracking in mass concrete foundation by circulating water, recorded a substantial effect at both the free surface and core of the mass concrete but little or no significance on part adjacent to ground surface. [7] conducted finite element simulation of early age temperature distribution in thick raft. The objective of the paper is to develop a mathematical model to predict the time dependent temperature profile in early age mass concrete.

\section{Methodology}

A block of size $1.1 \mathrm{~m} \times 1.1 \mathrm{~m} \times 1.1 \mathrm{~m}$, mix ratio of $1: 2: 4$ and water cement ratio of 0.6 whose ingredients comprises ordinary Portland cement, fine sand and crushed granite of $40 \mathrm{~mm}$ maximum size was used to verify the model. Type-K thermocouples positioned as shown in Fig. 1 and digital thermometer (Fig. 2) were used to monitor the temperature within the concrete mass at time intervals of 0, 6, 12, 18, 24, 48, 72, 96, 120 and 144 hours respectively. 


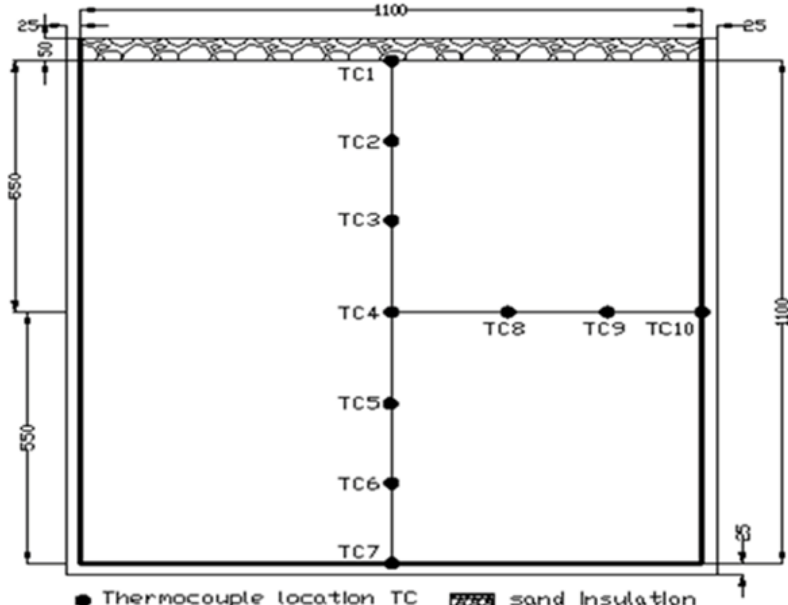

Fig. 1: Mass Concrete Block Showing the Layout of the Thermocouples. (All Dimensions in Mm)

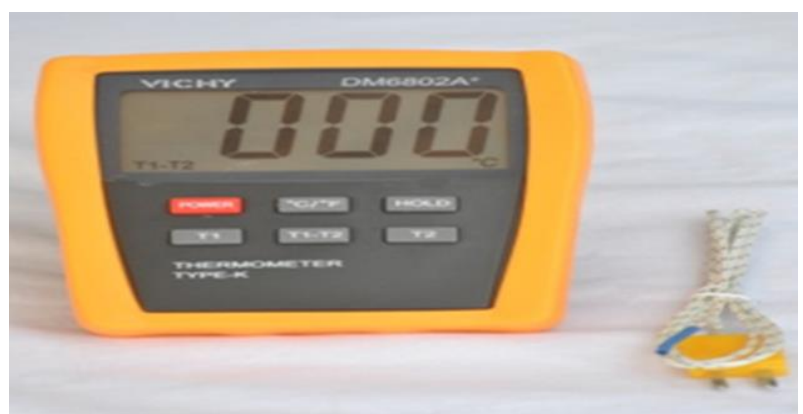

Fig. 2: Digital Thermometer and Type-K Thermocouple.

Fig. 1 shows plywood formwork of $25 \mathrm{~mm}$ thickness internally surrounded by polystyrene sheet as insulation and the top surface of the cast concrete covered with $50 \mathrm{~mm}$ thick layer of sand. The cast mass concrete formwork and thermocouple wires are shown in Fig. 3.

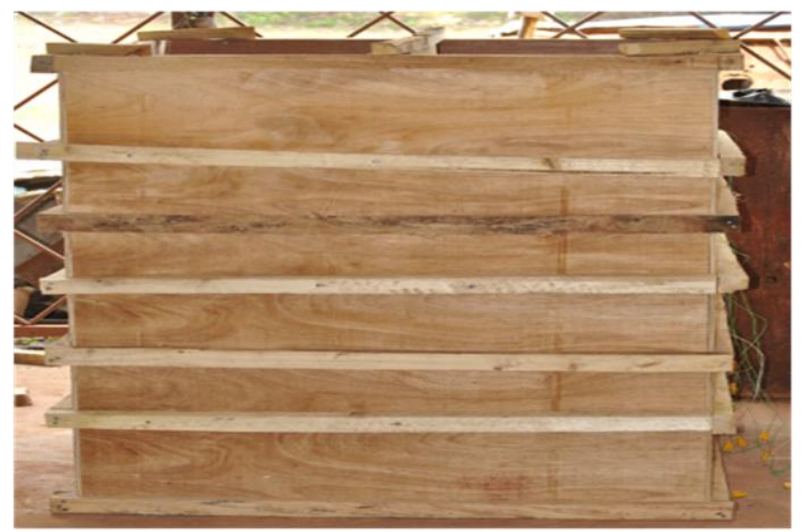

Fig. 3: Cast Mass Concrete Showing the Thermocouples.

\subsection{Model development}

Generally, problems encountered in the course of engineering practice are transformed into mathematical descriptions (models) of real life situations and systems. Such mathematical descriptions are often differential equations with assumed boundary and initial conditions. Differential equations are arrived at by subjecting the engineering systems to the laws and principles guiding the study of natural science. The governing equation shown in Eq (1) is that of two dimensional unsteady state heat conduction equation based on Fourier law of heat transfer.

$\mathrm{K}\left(\frac{\partial^{2} \mathrm{~T}}{\partial \mathrm{x}^{2}}+\frac{\partial^{2} \mathrm{~T}}{\partial \mathrm{y}^{2}}\right)+\mathrm{q}=\rho \operatorname{Cp} \frac{\partial \mathrm{T}}{\partial \mathrm{t}}$

$\rho$ is density of concrete $\left(\mathrm{kg} / \mathrm{m}^{3}\right), \mathrm{C}_{\mathrm{P}}$ is the specific heat capacity of concrete $\left(\mathrm{J} / \mathrm{kg} .{ }^{0} \mathrm{C}\right), \mathrm{q}$ is the heat source intensity $\left(\mathrm{KJ} / \mathrm{m}^{3} \cdot \mathrm{h}\right), \mathrm{K}$ is the thermal conductivity $\left(\mathrm{KJ} / \mathrm{m} \cdot \mathrm{h}^{0} \mathrm{C}\right)$, T is transient temperature of concrete $\left({ }^{\circ} \mathrm{C}\right)$ and $\mathrm{t}$ is time $(\mathrm{hrs})$.

At $\mathrm{t}=0$, there exists a uniform temperature.

For $\mathrm{t} \geq 0$, the initial conditions at $\mathrm{t}=0$;

$\mathrm{T}(\mathrm{x}, \mathrm{y}, \mathrm{t}=0)=\mathrm{T}_{0}$

For thermal insulation, we have the following boundary conditions:

$\mathrm{x}$-direction: $0 \leq \mathrm{x} \leq \mathrm{a}$, 
$\left.\frac{\partial \mathrm{T}}{\partial \mathrm{x}}\right|_{\mathrm{x}=0}=0$ and $\left.\frac{\partial \mathrm{T}}{\partial \mathrm{x}}\right|_{\mathrm{x}=\mathrm{a}}=0$

y-direction: $0 \leq \mathrm{y} \leq \mathrm{b}$,

$\left.\frac{\partial \mathrm{T}}{\partial \mathrm{y}}\right|_{\mathrm{y}=0}$ and $\left.\frac{\partial \mathrm{T}}{\partial \mathrm{y}}\right|_{\mathrm{y}=\mathrm{b}}=0$.

Let the solution of $\mathrm{Eq}$ (1) be

$\mathrm{T}(\mathrm{x}, \mathrm{y}, \mathrm{t})=\mathrm{T}_{\text {hom }}(\mathrm{x}, \mathrm{y}, \mathrm{t})+\mathrm{T}_{\text {inhom }}(\mathrm{x}, \mathrm{y}, \mathrm{t})$.

For homogeneous problem, we have

$\mathrm{k}\left(\frac{\partial^{2} \mathrm{~T}}{\partial \mathrm{x}^{2}}+\frac{\partial^{2} \mathrm{~T}}{\partial \mathrm{y}^{2}}\right)=\rho \mathrm{C}_{\rho} \frac{\partial \mathrm{T}}{\partial \mathrm{t}}$

To find the solution of the homogeneous problem, we use the method of separation of variables. Therefore, let

$\mathrm{T}_{\text {hom }}(\mathrm{x}, \mathrm{y}, \mathrm{t})=\mathrm{U}(\mathrm{x}) \cdot \mathrm{V}(\mathrm{y}) \cdot \mathrm{W}(\mathrm{t})$

Differentiating Eq (7) partially and substituting in Eq (6), we have

$\mathrm{k}\left[\mathrm{U}^{\prime \prime}(\mathrm{x}) \cdot \mathrm{V}(\mathrm{y}) \cdot \mathrm{W}(\mathrm{t})+\mathrm{U}(\mathrm{x}) \cdot \mathrm{V}^{\prime \prime}(\mathrm{y}) \cdot \mathrm{W}(\mathrm{t})\right]=\rho \mathrm{C}_{\rho} \mathrm{U}(\mathrm{x}) \cdot \mathrm{V}(\mathrm{y}) \cdot \mathrm{W}^{\prime}(\mathrm{t})$

Dividing both side of Eq (8) by $U(x) . V(y) . W(t)$, we have

$\mathrm{k}\left(\frac{\mathrm{U}^{\prime \prime}(\mathrm{x})}{\mathrm{U}(\mathrm{x})}+\frac{\mathrm{V}^{\prime \prime}(\mathrm{y})}{\mathrm{V}(\mathrm{y})}\right)=\rho \mathrm{C}_{\rho} \frac{\mathrm{W}^{\prime}(\mathrm{t})}{\mathrm{W}(\mathrm{t})}$

$\Rightarrow \frac{\mathrm{U}^{\prime \prime}(\mathrm{x})}{\mathrm{U}(\mathrm{x})}+\frac{\mathrm{V}^{\prime \prime}(\mathrm{y})}{\mathrm{V}(\mathrm{y})}=\frac{\rho \mathrm{C}_{\rho}}{\mathrm{k}} \frac{\mathrm{W}^{\prime}(\mathrm{t})}{\mathrm{W}(\mathrm{t})}$

Eq (10) means that

$\frac{\mathrm{u}^{\prime \prime}(\mathrm{x})}{\mathrm{U}(\mathrm{x})}=-\mathrm{c}, \frac{\mathrm{V}^{\prime \prime}(\mathrm{y})}{\mathrm{V}(\mathrm{y})}=-\mathrm{d}, \frac{\rho \mathrm{C}_{\rho}}{\mathrm{k}} \frac{\mathrm{W}^{\prime}(\mathrm{t})}{\mathrm{W}(\mathrm{t})}=-(\mathrm{c}+\mathrm{d})$,

Where $\mathrm{c}$ and $\mathrm{d}$ are separation constants.

Solution in $\mathrm{x}$-domain:

$\frac{\mathrm{U}^{\prime \prime}(\mathrm{x})}{\mathrm{U}(\mathrm{x})}=-\mathrm{c} \Rightarrow \mathrm{U}^{\prime \prime}(\mathrm{x})+\mathrm{cU}(\mathrm{x})=0$

Characteristic equation implies $m^{2}+c=0 \Rightarrow m= \pm i \sqrt{c}$.

$\mathrm{U}(x)=A \cos \sqrt{c} x+B \sin \sqrt{c} x$

$U^{\prime}(x)=\sqrt{c}[-A \sin \sqrt{c} x+B \cos \sqrt{c} x]$

$U^{\prime}(0)=0 \Rightarrow B=0$

$U^{\prime}(a)=0 \Rightarrow c=\left(\frac{n \pi}{a}\right)^{2}$

Solution in y-domain:

$\frac{V^{\prime \prime}(y)}{V(y)}=-d \Rightarrow V^{\prime \prime}(y)+d V(y)=0$

Characteristic equation implies $m^{2}+d=0 \Rightarrow m= \pm i \sqrt{d}$.

$V(y)=C \cos \sqrt{d} y+D \sin \sqrt{d} y$

$V^{\prime}(y)=\sqrt{d}[-C \sin \sqrt{d} y+D \cos \sqrt{d} y]$

$V^{\prime}(0)=0 \Rightarrow C=0$

$V^{\prime}(b)=0 \Rightarrow d=\left[\frac{(2 m+1) \pi}{2 b}\right]^{2}$

Solution in t-domain: 
$\frac{\rho C_{\rho}}{k} \frac{W^{\prime}(t)}{W(t)}=-(c+d) \Rightarrow W^{\prime}(t)=-\frac{k}{\rho C_{\rho}}(c+d) W(t)$

$\Rightarrow W(t)=E e^{-\left[\frac{k}{\rho c_{\rho}}(c+d)\right]}$

Putting Eq (13), (14), (16), (17) and (18) together, we have the homogeneous temperature as

$T_{\text {hom }}(x, y, t)=\sum_{n=0}^{\infty} \sum_{m=0}^{\infty} G_{m n} e^{-\left[\frac{k}{\rho C_{\rho}}(c+d)\right] t} \cos \left(\frac{n \pi}{a} x\right) \sin \frac{(2 m+1) \pi}{2 b} y$

For inhomogeneous problem, we use the solution found in homogeneous problem.

We now let

$T_{\text {inhom }}(x, y, t)=\sum_{n=0}^{\infty} \sum_{m=0}^{\infty} G_{m n}(t) e^{-\left[\frac{k}{\rho C_{\rho}}(c+d)\right] t} \cos \left(\frac{n \pi}{a} x\right) \sin \frac{(2 m+1) \pi}{2 b} y$,

which means that $G_{m n}(t)$ is now time dependent. Substituting Eq (20) in Eq (1), we have

$\frac{\partial^{2}}{\partial x^{2}}\left\{\sum_{n=0}^{\infty} \sum_{m=0}^{\infty} G_{m n}(t) e^{-\left[\frac{k}{\rho C_{\rho}}(c+d)\right] t} \cos \left(\frac{n \pi}{a} x\right) \sin \frac{(2 m+1) \pi}{2 b} y\right\}+\frac{\partial^{2}}{\partial y^{2}}\left\{\sum_{n=0}^{\infty} \sum_{m=0}^{\infty} G_{m n}(t) e^{-\left[\frac{k}{\rho c_{\rho}}(c+d)\right] t} \cos \left(\frac{n \pi}{a} x\right) \sin \frac{(2 m+1) \pi}{2 b} y\right\}+$

$20000 e^{\left(-0.9398-\frac{t}{24}\right)}=\frac{\rho C_{\rho}}{k} \frac{\partial}{\partial t}\left\{\sum_{n=0}^{\infty} \sum_{m=0}^{\infty} G_{m n}(t) e^{-\left[\frac{k}{\rho C_{\rho}}(c+d)\right] t} \cos \left(\frac{n \pi}{a} x\right) \sin \frac{(2 m+1) \pi}{2 b} y\right\}$

Suzuki's model, in [8] was adopted in which.

$q=20,000 e^{-0.9398-\frac{t}{24}}$

$q$ is the heat generated per unit volume of concrete in thours

But

$\frac{\partial^{2}}{\partial x^{2}}\left\{\sum_{n=0}^{\infty} \sum_{m=0}^{\infty} G_{m n}(t) e^{-\left[\frac{k}{\rho C_{\rho}}(c+d)\right] t} \cos \left(\frac{n \pi}{a} x\right) \sin \frac{(2 m+1) \pi}{2 b} y\right\}=\sum_{m, n=0}^{\infty}-G_{m n}(t) e^{-\left[\frac{k}{\rho C_{\rho}}(a+b)\right] t}\left(\frac{n \pi}{a}\right)^{2} \cos \left(\frac{n \pi}{a} x\right) \sin \frac{(2 m+1) \pi}{2 b} y$

Using Eq (14), we have

$\frac{\partial^{2}}{\partial x^{2}}\left\{\sum_{n=0}^{\infty} \sum_{m=0}^{\infty} G_{m n}(t) e^{-\left[\frac{k}{\rho C_{\rho}}(c+d)\right] t} \cos \left(\frac{n \pi}{a} x\right) \sin \frac{(2 m+1) \pi}{2 b} y\right\}=\sum_{m, n=0}^{\infty}-G_{m n}(t) e^{-\left[\frac{k}{\rho C_{\rho}}(c+d)\right] t} c \cos \left(\frac{n \pi}{a} x\right) \sin \frac{(2 m+1) \pi}{2 b} y$,

$\frac{\partial^{2}}{\partial y^{2}}\left\{\sum_{n=0}^{\infty} \sum_{m=0}^{\infty} G_{m n}(t) e^{-\left[\frac{k}{\rho C_{\rho}}(c+d)\right] t} \cos \left(\frac{n \pi}{a} x\right) \sin \frac{(2 m+1) \pi}{2 b} y\right\}=\sum_{m, n=0}^{\infty}-G_{m n}(t) e^{-\left[\frac{k}{\rho C_{\rho}}(c+d)\right] t}\left[\frac{(2 m+1) \pi}{2 b}\right]^{2} \cos \left(\frac{n \pi}{a} x\right) \sin \frac{(2 m+1) \pi}{2 b} y$.

Using Eq (17), we have

$\frac{\partial^{2}}{\partial y^{2}}\left\{\sum_{n=0}^{\infty} \sum_{m=0}^{\infty} G_{m n}(t) e^{-\left[\frac{k}{\rho c_{\rho}}(c+d)\right] t} \cos \left(\frac{n \pi}{a} x\right) \sin \frac{(2 m+1) \pi}{2 b} y\right\}$

$=\sum_{m, n=0}^{\infty}-G_{m n}(t) e^{-\left[\frac{k}{\rho C_{\rho}}(c+d)\right] t} d \cos \left(\frac{n \pi}{a} x\right) \sin \frac{(2 m+1) \pi}{2 b} y$,

And

$\frac{\rho C_{\rho}}{k} \frac{\partial}{\partial t}\left\{\sum_{n=0}^{\infty} \sum_{m=0}^{\infty} G_{m n}(t) e^{-\left[\frac{k}{\rho C_{\rho}}(c+d)\right] t} \cos \left(\frac{n \pi}{L} x\right) \sin \frac{(2 m+1) \pi}{2 b} y\right\}=\frac{\rho C_{\rho}}{k} \sum_{m, n=0}^{\infty}\left\{G_{m n}^{\prime}(t) e^{-\left[\frac{k}{\rho C_{\rho}}(c+d)\right] t} \cos \left(\frac{n \pi}{a} x\right) \sin \frac{(2 m+1) \pi}{2 b} y-\right.$

$\left.\left[\frac{k}{\rho C_{\rho}}(c+d)\right] G_{m n}(t) e^{-\left[\frac{k}{\rho C_{\rho}}(c+d)\right] t} \cos \left(\frac{n \pi}{a} x\right) \sin \frac{(2 m+1) \pi}{2 b} y\right\}$

$=\sum_{m, n=0}^{\infty}\left\{\frac{\rho C_{\rho}}{k} G_{m n}^{\prime}(t)-(c+d) G_{m n}(t)\right\} e^{-\left[\frac{k}{\rho C_{\rho}}(c+d)\right] t} \cos \left(\frac{n \pi}{a} x\right) \sin \frac{(2 m+1) \pi}{2 b} y$.

Putting the results of Eq (23), (24) and (25) together in Eq (21), we have

$\sum_{m, n=0}^{\infty} \frac{\rho C_{\rho}}{k} G_{m n}^{\prime}(t) \cos \left(\frac{n \pi}{a} x\right) \sin \frac{(2 m+1) \pi}{2 b} y=20000 e^{\left(-0.9398-\left[\frac{1}{24}-\frac{k}{\rho C_{\rho}}(c+d)\right] t\right)}$

The orthogonality relations can help to find an equation to determine $G_{m n}^{\prime}(t)$ with simple and direct integration. Now using the orthogonality relations, we have

$\sum_{m, n=0}^{\infty} \frac{\rho C_{\rho}}{k} G_{m n}^{\prime}(t) \int_{0}^{l} \cos \left(\frac{n \pi}{a} x\right) \cos \left(\frac{k \pi}{b} x\right) d x \times \int_{0}^{l} \sin \frac{(2 m+1) \pi}{2 b} y \sin \frac{(2 p+1) \pi}{2 b} y d y=$

$20000 e^{\left(-0.9398-\left[\frac{1}{24}-\frac{k}{\rho C_{\rho}}(c+d)\right] t\right)} \int_{0}^{l} \cos \left(\frac{k \pi}{a} x\right) \sin \frac{(2 p+1) \pi}{2 b} y$.

But 
$\int_{0}^{l} \cos \left(\frac{n \pi}{a} x\right) \cos \left(\frac{k \pi}{a} x\right) d x=\frac{L}{2} \delta_{k n}$

And

$\int_{0}^{l} \sin \frac{(2 m+1) \pi}{2 b} y \sin \frac{(2 p+1) \pi}{2 b} y d y=\frac{L}{2} \delta_{m p}$,

Where $\delta$ is the Kroneker symbol and is defined as

$\delta_{i j}=\left\{\begin{array}{cc}1 & i=j \\ 0 & i \neq j\end{array}\right.$

Substituting Eq (28) and (29) in Eq (27), we have

$\sum_{m, n=0}^{\infty} \frac{\rho C_{\rho}}{k} G_{m n}^{\prime}(t) \frac{L}{2} \delta_{k n} \frac{L}{2} \delta_{m p}=20000 e^{\left(-0.9398-\left[\frac{1}{24}-\frac{k}{\rho C \rho}(c+d)\right] t\right)} L \delta_{k 0} \frac{2 L}{\pi(2 p+1)}$

For $L=1, m=p$ and $k=n$, then

$G_{p k}^{\prime}(t)=-4 \times \frac{k}{\rho C_{\rho}} \times 20000 e^{\left(-0.9398-\left[\frac{1}{24}-\frac{k}{\rho C_{\rho}}(c+d)\right] t\right)} \delta_{k 0} \frac{2}{\pi(2 p+1)} \Rightarrow$

$G_{p k}^{\prime}(t)=-\frac{k}{\rho C_{\rho}} e^{\left(-0.9398-\left[\frac{1}{24}-\frac{k}{\rho C_{\rho}}(c+d)\right] t\right)} \delta_{k 0} \frac{160000}{\pi(2 p+1)}$

For $k \neq 0$,

$G_{p k}^{\prime}(t)=0 \Rightarrow G_{p k}(t)=C_{p k}=$ Constant

For $k=0$,

$G_{p k}^{\prime}(t)=-\frac{k}{\rho C_{\rho}} e^{\left(-0.9398-\left[\frac{1}{24}-\frac{k}{\rho C_{\rho}}(c+d)\right] t\right)} \frac{160000}{\pi(2 p+1)} \Rightarrow$

$G_{p k}(t)=\frac{k}{\rho C_{\rho}} e^{\left(-0.9398-\left[\frac{1}{24}-\frac{k}{\rho C_{\rho}}(c+d)\right] t\right)} \frac{20000}{3 \pi(2 p+1)}+C_{2}$

We now choose $C_{2}=0$ without loss of generality. Putting all together we get

$T_{\text {inhom }}(x, y, t)=\sum_{n=0}^{\infty} \sum_{m=0}^{\infty} C_{m n} e^{-\left[\frac{k}{\rho C_{\rho}}(c+d)\right] t} \cos \left(\frac{n \pi}{a} x\right) \sin \frac{(2 m+1) \pi}{2 b} y+\sum_{m=0}^{\infty} \frac{k}{\rho C_{\rho}} e^{\left(-0.9398-\left[\frac{1}{24}-\frac{k}{\rho C_{\rho}}(c+d)\right] t\right)} \frac{20000}{3 \pi(2 m+1)} \sin \frac{(2 m+1) \pi}{2 a} y$

The solution is $T(x, y, t)=T_{\text {hom }}(x, y, t)+T_{\text {inhom }}(x, y, t)$.

Therefore,

$T(x, y, t)=\sum_{n=0}^{\infty} \sum_{m=0}^{\infty} G_{m n} e^{-\left[\frac{k}{\rho C_{\rho}}(c+d)\right] t} \cos \left(\frac{n \pi}{a} x\right) \sin \frac{(2 m+1) \pi}{2 b} y+\sum_{n=0}^{\infty} \sum_{m=0}^{\infty} C_{m n} e^{-\left[\frac{k}{\rho C \rho}(c+d)\right] t} \cos \left(\frac{n \pi}{a} x\right) \sin \frac{(2 m+1) \pi}{2 b} y+$ $\sum_{m=0}^{\infty} \frac{k}{\rho C_{\rho}} e^{\left(-0.9398-\left[\frac{1}{24}-\frac{k}{\rho c_{\rho}}(c+d)\right] t\right)} \frac{20000}{3 \pi(2 m+1)} \sin \frac{(2 m+1) \pi}{2 b} y \Rightarrow$

$T(x, y, t)=\sum_{n=0}^{\infty} \sum_{m=0}^{\infty}\left(G_{m n}+C_{m n}\right) e^{-\left[\frac{k}{\rho C \rho}(c+d)\right] t} \cos \left(\frac{n \pi}{a} x\right) \sin \frac{(2 m+1) \pi}{2 b} y+$

$\sum_{m=0}^{\infty} \frac{k}{\rho C_{\rho}} e^{\left(-0.9398-\left[\frac{1}{24}-\frac{k}{\rho C \rho}(c+d)\right] t\right)} \frac{20000}{3 \pi(2 m+1)} \sin \frac{(2 m+1) \pi}{2 b} y$

Now, what is required is to obtain the value of $G_{m n}+C_{m n}=D_{m n}$.

The initial conditions at $t=0 \Rightarrow T(x, y, t=0) \equiv T_{0}$

$T(x, y, t=0)=\sum_{n=0}^{\infty} \sum_{m=0}^{\infty} D_{m n} \cos \left(\frac{n \pi}{a} x\right) \sin \frac{(2 m+1) \pi}{2 b} y+\sum_{m=0}^{\infty} \frac{k}{\rho C_{\rho}} e^{(-0.9398)} \frac{20000}{3 \pi(2 m+1)} \sin \frac{(2 m+1) \pi}{2 b} y=T_{0}$.

Using the orthogonality relations, we have

$\sum_{n=0}^{\infty} \sum_{m=0}^{\infty} D_{m n} \int_{0}^{l} \cos \left(\frac{n \pi}{a L} x\right) \cos \left(\frac{k \pi}{a} x\right) d x \times \int_{0}^{l} \sin \frac{(2 m+1) \pi}{2 b} y \sin \frac{(2 p+1) \pi}{2 b} y d y+$

$\sum_{m=0}^{\infty} \frac{k}{\rho C_{\rho}} e^{(-0.9398)} \frac{20000}{3 \pi(2 m+1)} \int_{0}^{l} \sin \frac{(2 m+1) \pi}{2 b} y \sin \frac{(2 p+1) \pi}{2 b} y d y \times \int_{0}^{l} \cos \left(\frac{k \pi}{a} x\right) \sin \frac{(2 p+1) \pi}{2 a} y=T_{0} \int_{0}^{l} \cos \left(\frac{k \pi}{a} x\right) \sin \frac{(2 p+1) \pi}{2 b} y \Rightarrow$

$\sum_{n=0}^{\infty} \sum_{m=0}^{\infty} D_{m n} \frac{L}{2} \delta_{k n} \frac{L}{2} \delta_{m p}+\sum_{m=0}^{\infty} \frac{k}{\rho C_{\rho}} e^{(-0.9398)} \frac{20000}{3 \pi(2 m+1)} \frac{L}{2} \delta_{m p} L \delta_{k 0} \frac{2 L}{\pi(2 p+1)}=T_{0} L \delta_{k 0} \frac{2 L}{\pi(2 p+1)}$ 
For $L=1, m=p$ and $k=n$, then we have

$D_{p k}=T_{0} \delta_{k 0} \frac{8}{\pi(2 p+1)}-\frac{k}{\rho C_{\rho}} e^{(-0.9398)} \frac{80000}{3[\pi(2 p+1)]^{2}} \delta_{k 0}$

For $k \neq 0$,

$D_{p k}=0$

For $k=0$,

$D_{p k}=T_{0} \frac{8}{\pi(2 p+1)}-\frac{k}{\rho C_{\rho}} e^{(-0.9398)} \frac{80000}{3[\pi(2 p+1)]^{2}}$.

Hence,

$T(x, y, t)=$

$\sum_{n=0}^{\infty} \sum_{m=0}^{\infty}\left[T_{0} \frac{8}{\pi(2 m+1)}-\frac{k}{\rho C_{p}} e^{(-0.9398)} \frac{80000}{3[\pi(2 m+1)]^{2}}\right] e^{-\left[\frac{k}{\rho C_{p}}(c+d)\right] t} \operatorname{Cos}\left(\frac{n \pi}{a} x\right) \operatorname{Sin} \frac{(2 m+1) \pi}{2 b} y+$

$\sum_{n=0}^{\infty} \sum_{m=0}^{\infty} \frac{k}{\rho C_{p}} e^{\left(-0.9398-\left[\frac{1}{24}-\frac{k}{\rho C_{p}}(c+d)\right] t\right)} \frac{20000}{3 \pi(2 m+1)} \operatorname{Sin} \frac{(2 m+1) \pi}{2 b} y$

\section{Results}

The temperature values for the various thermocouple locations within the mass concrete block used for the model verification were recorded for the various time intervals. Fig. $4 \mathrm{a}$ and Fig. $4 \mathrm{~b}$ show the graphs of temperature against time for the various thermocouple locations. The zero hour temperature signifies the temperature of the mass concrete block immediately after placement which was found to be uniform throughout the various locations at $28^{\circ} \mathrm{C}$.

The temperature distribution indicates that the mass concrete exhibited higher temperature values within the core (TC3, TC4, TC5 and TC8) and the least values at locations close to the surface (TC1, TC7 and TC10) for all time intervals. After 120 hours of concrete placement, a constant temperature of $32^{\circ} \mathrm{C}$ was subsequently recorded for all thermocouple locations. The surface of the mass concrete in contact with the ground exhibited lower temperatures than other surfaces for most of the time intervals. Generally the temperature readings showed a rise from a uniform placement temperature of $28^{\circ} \mathrm{C}$ to the peak temperature of $51^{\circ} \mathrm{C}$ at the core within 24 hours of concrete placement and fall afterwards to $32^{\circ} \mathrm{C}$ at both 120 and 144 hours respectively. This is in agreement with the findings of previous authors in literature [7], [8], [10].

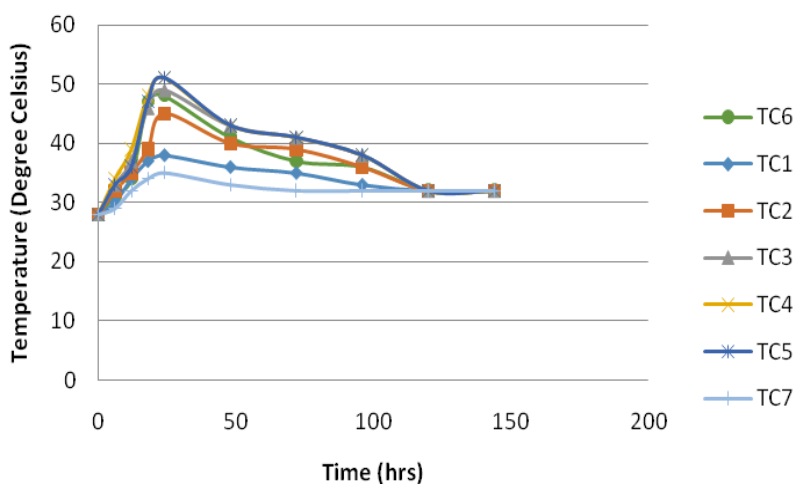

Fig. 4: A) Temperature Time Relationship for Thermocouple Locations (TC1 To TC7).

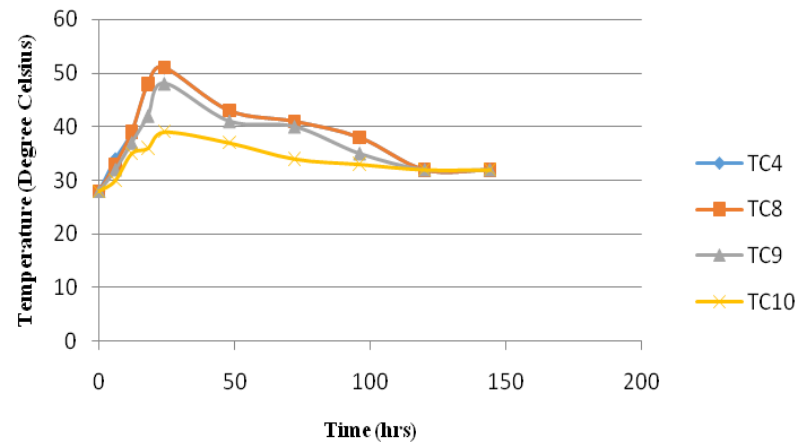

Fig. 4: B) Temperature Time Relationship for Thermocouple Locations (TC4, TC8, TC9 and TC10).

\subsection{Calibration}

Thermal conductivity $(\mathrm{K})$ as a property of concrete depends on its material composition, its values range between 7.1 to $10.6 \mathrm{KJ} / \mathrm{mh}{ }^{0} \mathrm{C}$ according to ACI committee 207, 2005b in [8]. Thermal conductivity value of $9 \mathrm{KJ} / \mathrm{mh}^{0} \mathrm{C}$ was used in the research. According to ACI 
committee $207,2005 \mathrm{~b}$ in [8], the thermal conductivity of concrete ranges between 0.90 to $1.0 \mathrm{KJ} / \mathrm{kg}^{0} \mathrm{C}$. A specific value of $0.9 \mathrm{KJ} / \mathrm{kg}^{0} \mathrm{C}$ was adopted for the research. The density of fresh, normal weight concrete is generally $2400 \mathrm{~kg} / \mathrm{m}^{3}$. The initial temperature $\left(\boldsymbol{T}_{\mathbf{0}}\right)$ was assumed to be placement temperature with a value of $28^{\circ} \mathrm{C}$.

\subsection{Verification}

The analytical model developed (Eq (36)) is based on the two dimensional unsteady state heat conduction within the mass concrete with constant temperature boundary and initial condition was verified using the experimental mass concrete block. A MATLAB based computer program was used to evaluate the model. The programe was designed with the capability of iteration which will continue until a temperature value of $0.0001^{\circ} \mathrm{C}$ after which the iteration will cease and the temperature aggregated and determined for each time interval.

Fig. 5 shows the plot of temperature time relationship for observed temperature values from the mass concrete block experiment and that predicted using the developed analytical model at early ages of cement hydration. The model exhibited higher temperature values than the experimental observed temperatures except for the placement temperature at the initial time which had a lower value of $27.7^{\circ} \mathrm{C}$ than the experimental temperature which was $28^{\circ} \mathrm{C}$. However both graphs show the highest temperature values at 24 hours concrete placement of $60.71^{\circ} \mathrm{C}$ and $51^{\circ} \mathrm{C}$ for the model and the experiment respectively. Fig. 6 shows the coefficient of determination $\mathrm{R}^{2}$ for the model verification with value of 0.912 which gives a correlation coefficient CORR value of 0.95 representing a high correlation of the model.

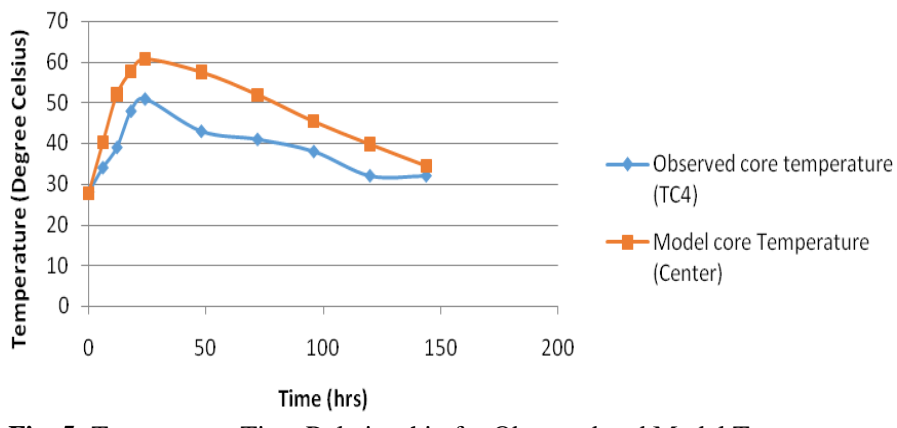

Fig. 5: Temperature Time Relationship for Observed and Model Temperatures.

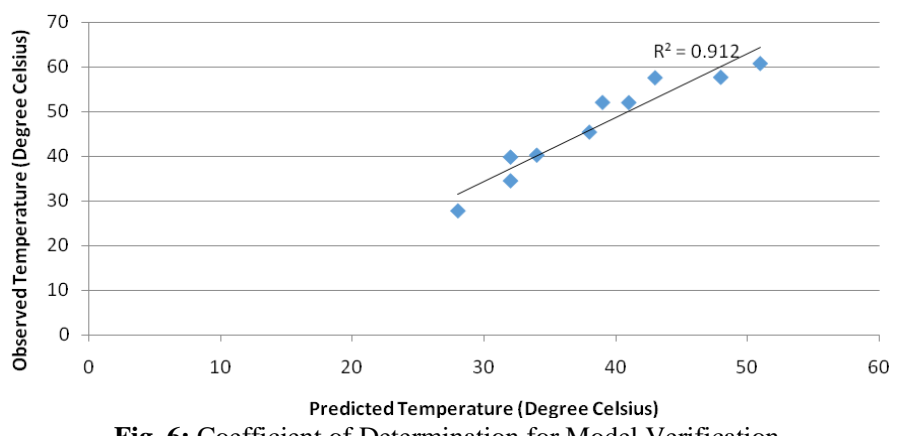

Fig. 6: Coefficient of Determination for Model Verification.

\subsection{Validation}

The model was validated using the temperature data from [10]. The experimental procedure involved the casting of $1.5 \mathrm{~m} \times 1.5 \mathrm{~m} \times 1.5 \mathrm{~m}$ mass concrete cube, using a plywood formwork and polystyrene sheet and sand as insulation. The temperature data obtained from the thermocouple positioned at the mid-section (i.e. $\mathrm{x}=\mathrm{y}=0.75 \mathrm{~m}$ ) of the concrete cube was used to validate the model. The temperature was recorded at $0,12,18,24,48,72,96$ and 120 hours. The predicted temperature data from the analytical model developed was obtained from the evaluation of the model solution in Equation 36 using a MATLAB based program.

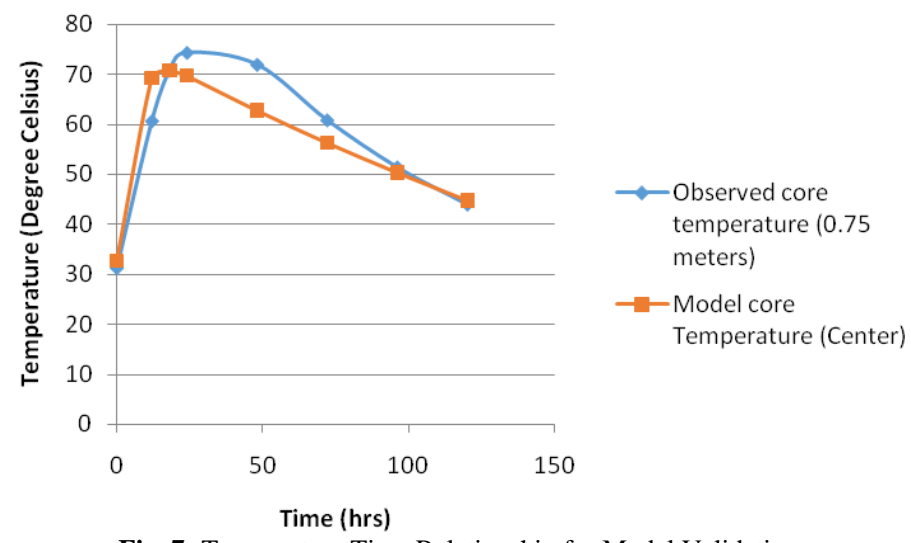

Fig. 7: Temperature Time Relationship for Model Validation. 


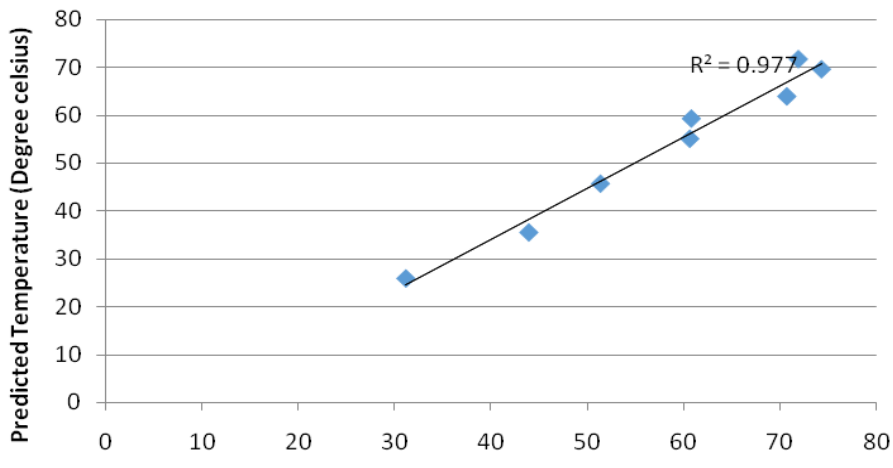

Observed Temperature (Degrees Celsius)

Fig. 8: Coefficient of Determination for Observed and Predicted Temperatures.

A comparison of the two plots in Fig. 7 shows that the model adequately predicted the temperature variation within the mass concrete cube with time. The peak temperatures occur at $24 \mathrm{hrs}$ for the observed data and $48 \mathrm{hrs}$ for the model predicted data. Also the model data was generally lower than that of experimental data for all time intervals. These discrepancies are attributable to inaccurate values adopted in the model calibration and other environmental conditions that affect the experimental procedures. Fig. 8 shows a coefficient of determination $\mathrm{R}^{2}$ value of 0.977 , giving correlation coefficient CORR value of 0.98 . This is a reliable indication that the model predicted data adequately correlated with the experimental observed data.

\section{Conclusion}

Ease of use, accuracy and applicability are among the attributes that determine the success of a model. The analytical model developed was successfully applied in the prediction of time dependent temperature profile in early age mass concrete. The highest temperature values occurred within the core of the mass concrete at 24 hours of concrete placement. When the ambient temperature and the size of the mass concrete are known, the model has the capability of predicting the temperature distribution at intervals within the mass concrete. It is therefore suitable for use in the assessment and prediction of thermal cracks in mass concrete structures.

\section{Acknowledgement}

The authors appreciate the Department of Civil Engineering, University of Nigeria, Nsukka for their guidance and assistance towards the success of the research.

\section{References}

[1] S. Worapong, H. Nakamura, M. Kunieda, Y. Ishikawa, Analysis of crack propagation due to thermal stress in concrete considering slodified constitutive model, Journal of Advanced Concrete Technology, 5 (1) (2007) 99-112. https://doi.org/10.3151/jact.5.99.

[2] B. Klemczak, A. Knoppik-Wrobel, Numerical model for analysis of early-age thermal-moisture effects in an RC wall, Technical Transactions, Civil Engineering, 1-B (2003) 99-113.

[3] L. Jendele, V. Smilauer, J. Cervenka, Multi-scale analysis of heat transport in hydrating concrete structures, Proceedings of the Thirteenth International Conference on Civil, Structural and Environmental Engineering Computing, Civil-Comp Press, Stirlingshere, paper 124, Scotland, (2011),

[4] M. H. Lee, B. S. Khil, H. D. Yun, Influence of cement type on heat of hydration and temperature rise of the mass concrete, Indian Journal of Engineering \& Material Sciences, 21 (2014) 536-542.

[5] D. S. Guo, E. Y. Chen, G. L. Low, J. L. Yang, Experimental modeling of temperature rise of mass concrete by FDM method, 26th Conference on Our World in Concrete \& Structures, (2001) 261-267.

[6] W. Liu, W. Cao, H. Yan, T. Ye, W. Jia, Experimental and numerical studies of controlling cracks in mass concrete foundation by circulating water, Applied Sciences, 6 (110) (2016) 1-18. https://doi.org/10.3390/app6040110.

[7] B. Kuriakose, B. N. Rao, G. R. Dodagoudar, Modeling of early age concrete temperature distribution in thick rafts, $5^{\text {th }}$ International Congress on Computational Mechanics and Simulation, (2014) 10 -13. https://doi.org/10.3850/978-981-09-1139-3_294.

[8] H. Abeka, S. Agyeman, M. A. Asamoah, Thermal effect of mass concrete structures in the tropics: experimental, modeling and parametric studies, Cogent Engineering 4 (2017) 127829. https://doi.org/10.1080/23311916.2016.1278297.

[9] W. G. J. Prasanna, A. P. Subhashini, Cracking due to temperature gradient in concrete, International Conference on Sustainable Built Environment (ICSBE), Kandy, (2010) 496-504. 